\title{
Gene Expression in the Brain across the Hibernation Cycle
}

\author{
Bruce F. O'Hara, Fiona L. Watson, Hilary K. Srere, Himanshu Kumar, Steven W. Wiler, Susan K. Welch, \\ Louise Bitting, H. Craig Heller, and Thomas S. Kilduff \\ Center for Sleep and Circadian Neurobiology, Departments of Psychiatry and Behavioral Sciences and Biological \\ Sciences, Stanford University, Stanford, California 94305-5020
}

The purpose of this study was to characterize changes in gene expression in the brain of a seasonal hibernator, the goldenmantled ground squirrel, Spermophilus lateralis, during the hibernation season. Very little information is available on molecular changes that correlate with hibernation state, and what has been done focused mainly on seasonal changes in peripheral tissues. We produced over 4000 reverse transcription-PCR products from euthermic and hibernating brain and compared them using differential display. Twenty-nine of the most promising were examined by Northern analysis. Although some small differences were observed across hibernation states, none of the 29 had significant changes. However, a more direct approach, investigating expression of putative hibernationresponsive genes by Northern analysis, revealed an increase in expression of transcription factors c-fos, junB, and c-Jun, but not junD, commencing during late torpor and peaking during the arousal phase of individual hibernation bouts. In contrast, prostaglandin D2 synthase declined during late torpor and arousal but returned to a high level on return to euthermia. Other genes that have putative roles in mammalian sleep or specific brain functions, including somatostatin, enkephalin, growth-associated protein 43, glutamate acid decarboxylases $65 / 67$, histidine decarboxylase, and a sleep-related transcript SD464 did not change significantly during individual hibernation bouts. We also observed no decline in total RNA or total mRNA during torpor; such a decline had been previously hypothesized. Therefore, it appears that the dramatic changes in body temperature and other physiological variables that accompany hibernation involve only modest reprogramming of gene expression or steady-state mRNA levels.

Key words: prostaglandin D2; enkephalin; c-fos; immediate early genes; ddPCR; $m R N A$
Hibernation has fascinated people for centuries, but little is known about the mechanisms controlling the hibernation process in mammals. Contrary to popular belief, small hibernating mammals do not remain torpid throughout the hibernation season. These hibernators exhibit periodic bouts of torpor throughout the winter, marked by dramatic changes in physiological variables, such as body temperature $\left(\mathrm{T}_{\mathrm{b}}\right)$. Both entrance into and arousal from torpor are regulated processes controlled by hypothalamic nuclei and other brain structures (Heller et al., 1978; Kilduff et al., 1990). Neural activity, as well as all metabolic activity, is greatly reduced at the low temperatures associated with deep torpor (Walker et al., 1977; Heller, 1979; Krilowicz et al., 1988). Nevertheless, physiological regulation continues, and arousals appear to be precisely timed (Grahn et al., 1994). Given the duration and dramatic physiological changes that accompany hibernation events, changes in gene expression are probably involved.

In this study, two approaches were used to detect changes in gene expression during hibernation. First, random mRNAs were compared in brain samples from euthermic versus hibernating animals using a differential display PCR method (ddPCR). One advantage of this technique is that no prior assumptions are made

Received Oct. 5, 1998; revised Feb. 3, 1999; accepted March 9, 1999.

This work was supported by Army Research Office Grant DAAH04-95-1-0616, National Institutes of Health Grants DA00187 and HL58985, and a grant from the Upjohn Company. This article is dedicated to the memory of Louise Bitting (1/20/49 to $1 / 9 / 99$ ), whose creativity and love of science and life were an inspiration to all who knew her.

Correspondence should be addressed to Dr. Bruce F. O'Hara, Department of Biological Sciences, Stanford University, Stanford, CA 94305-5020.

Dr. Kilduff's present address: Molecular Neurobiology Laboratory, SRI International, Menlo Park, CA 94025.

Copyright @ 1999 Society for Neuroscience $0270-6474 / 99 / 193781-10 \$ 05.00 / 0$ as to which mRNAs are most likely to change. In the second approach, changes in abundance of specific mRNAs were tested by Northern analysis. The genes examined were selected based on expression patterns in brain and previous evidence for involvement in arousal state control.

Specifically, we chose six categories of genes. The first category is immediate early genes (IEGs). IEGs, including c-fos, junB, c-jun, junD, NGFI-A, and others, are transcription factors that respond to environmental stimulation within minutes. The role of IEG expression in the CNS has been well documented (Sheng and Greenberg, 1990; Morgan and Curran, 1991) and has been implicated in sleep, circadian rhythms, and hibernation (Sutin and Kilduff, 1992; Grassi-Zucconi et al., 1993; O’Hara et al., 1993, 1997; Bitting et al., 1994; Pompeiano et al., 1994). The second category includes enkephalin and somatostatin. Numerous studies have implicated the opioid system in hibernation and, to a lesser extent, somatostatin (Beckman et al., 1981, 1986; Beckman and Llados-Eckman, 1985; Nurnberger et al., 1991, 1997; Wang, 1993). The third is prostaglandin D2 (PGD2) synthase. PGD2 has been shown to increase seasonally in a hibernator (Takahata et al., 1996), induce sleep when injected intracerebroventricularly (Matsumura et al., 1994; Hayaishi, 1997; Ram et al., 1997), and reduce somatosensory pain perception (Minami et al., 1996). The fourth, the SD464 clone, was isolated by Rhyner et al. (1990) for its possible role in sleep homeostasis. The fifth category is glutamic acid decarboxylases GAD65 and GAD67 and histidine decarboxylase. GAD65 and GAD67 synthesize GABA (Erlander et al., 1991), the dominant inhibitory neurotransmitter in brain. Histidine decarboxylase produces histamine (Joseph et al., 1990), which may play a major role in arousal state control (Sherin et al., 


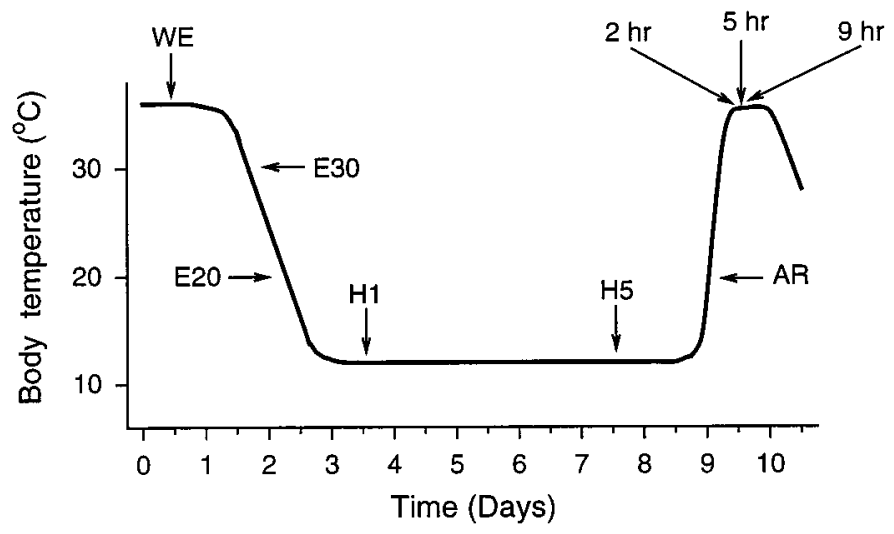

Figure 1. Schematic representation of a bout of torpor during the hibernation season. Bouts of torpor lasting several days to $>1$ week are interspersed with periodic returns to euthermia, referred to as winter euthermia or interbout euthermia. Arrows indicate times at which samples were taken. $W E$, Winter euthermic $\left(\mathrm{T}_{\mathrm{b}}\right.$ of $\left.37^{\circ} \mathrm{C}\right) ; E 30$, entrance $\left(\mathrm{T}_{\mathrm{b}}\right.$ of $\left.30^{\circ} \mathrm{C}\right) ; E 20$, entrance $\left(\mathrm{T}_{\mathrm{b}}\right.$ of $\left.20^{\circ} \mathrm{C}\right) ; H 1$, hibernation day $1\left(\mathrm{~T}_{\mathrm{b}}\right.$ of $\left.7^{\circ} \mathrm{C}\right) ; H 5$, hibernation day $5\left(\mathrm{~T}_{\mathrm{b}}\right.$ of $\left.7^{\circ} \mathrm{C}\right) ; A R$, arousal $\left(\mathrm{T}_{\mathrm{b}}\right.$ of $\left.20^{\circ} \mathrm{C}\right) ; 2 \mathrm{hr}, 5 \mathrm{hr}$, and 9 $h r$, refer to postarousal time $\left(\mathrm{T}_{\mathrm{b}}\right.$ of $\left.37^{\circ} \mathrm{C}\right)$ and are abbreviated in other figures as $P 2, P 5$, and $P 9$.

1998). The last is growth-associated protein 43 (GAP43). Changes in dendritic spines have been reported during torpor (Popov and Bocharova, 1992; Popov et al., 1992), and GAP43 is strongly associated with synaptic plasticity (Skene et al., 1986; Benowitz and Routtenberg, 1987; Neve et al., 1987).

\section{MATERIALS AND METHODS}

Animals. Golden-mantled ground squirrels, Spermophilus lateralis, were trapped during the summer months in Alpine and El Dorado Counties of the Sierra Nevada Mountains of California. Both male and female animals were used in this study. Animals were implanted with abdominal temperature transmitters (Mini-Mitter Co., Sunriver, OR), and $\mathrm{T}_{\mathrm{b}}$ was monitored continuously during the hibernation season. At the time the animals were killed, all $\mathrm{T}_{\mathrm{b}}$ measurements were confirmed with a thermocouple probe placed in one or more of the following locations: rectal, abdominal, thoracic, and occasionally into the brain. Temperature measurements in different locations were all similar, although the head is known to warm first during arousal. Animals were maintained at an ambient temperature of $5^{\circ} \mathrm{C}$ in a constant $12 \mathrm{hr}$ light/dark cycle (lights on at 8:00 A.M.). Animals were killed by decapitation during a $3 \mathrm{hr}$ "window" between 1:00 and 4:00 P.M. during lights on. Although circadian rhythms of temperature persist throughout the hibernation season (Grahn et al., 1994), the rhythms appear to be primarily desynchronized from the light cycle (Pohl, 1987; our unpublished observations). Most squirrels were killed in one of five phases of the hibernation cycle as indicated in Figure 1: (1) euthermia (winter) $\left(\mathrm{T}_{\mathrm{b}}\right.$ of $\left.37^{\circ} \mathrm{C}\right)$; (2) midentrance $\left(\mathrm{T}_{\mathrm{b}}\right.$ of $\left.20^{\circ} \mathrm{C}\right)$; (3) day 1 of deep hibernation $\left(\mathrm{T}_{\mathrm{b}}\right.$ of $\left.7-8^{\circ} \mathrm{C}\right) ;(4)$ day 4,5 , or 6 of deep hibernation $\left(\mathrm{T}_{\mathrm{b}}\right.$ of $\left.7-8^{\circ} \mathrm{C}\right)$; and $(5)$ midarousal from hibernation $\left(\mathrm{T}_{\mathrm{b}}\right.$ of $\left.20^{\circ} \mathrm{C}\right)$, which typically occurs $\sim 1 \mathrm{hr}$ after body temperature begins to rise. A smaller number of squirrels were killed during the summer active phase $\left(\mathrm{T}_{b}\right.$ of $\left.37^{\circ} \mathrm{C}\right)$ at early entrance $\left(\mathrm{T}_{b}\right.$ of $\left.30^{\circ} \mathrm{C}\right)$ or at 2,5 , or $9 \mathrm{hr}$ after arousal (from $\mathrm{T}_{\mathrm{b}}$ of $20^{\circ} \mathrm{C}$ ). The 2,5 , and 9 postarousal animals all had a $\mathrm{T}_{\mathrm{b}}$ of $37^{\circ} \mathrm{C}$ and were the same as other winter euthermic animals (sometimes called interbout animals), except that postarousal time was precisely determined. Summer active squirrels had not hibernated for at least 3 weeks. Approximately 50 squirrels were continuously monitored to obtain animal(s) at each specific phase, at the designated time of day.

$R N A$ isolation and Northern analysis. After decapitation, brains were rapidly removed and dissected into 12 subregions (hypothalamus, thalamus, cerebral cortex, basal forebrain, septum, hippocampus, striatum, midbrain, cerebellum, pons, medulla, and pineal). Many peripheral tissues were taken, as well. All tissues were frozen on dry ice and stored at $-70^{\circ} \mathrm{C}$. Total RNA was extracted using a guanidinium- $\mathrm{CsCl}$ method or Trizol (BRL, Grand Island, NY), fractionated on $1.2 \%$ formaldehydeagarose gels, and transferred to Nytran membranes (Schleicher \&
Schuell, Keene, NH). RNA was visualized by ethidium bromide staining and cross-linked by UV irradiation. After prehybridization, membranes were hybridized at $42^{\circ} \mathrm{C}$ in $5 \times \mathrm{SSC}, 50 \%$ formamide, $50 \mathrm{~mm}$ sodium phosphate, pH 6.8, $1 \%$ SDS, 1 mM EDTA, $2.5 \times$ Denhardt's solution, 200 $\mathrm{mg} / \mathrm{ml}$ herring sperm DNA, and 4-10 $\times 10^{6} \mathrm{cpm} / \mathrm{ml}{ }^{32}$ P-radiolabeled random-primed cDNA probe. After hybridization, membranes were washed two times for $30 \mathrm{~min}$ at $58^{\circ} \mathrm{C}$ in $0.4 \times \mathrm{SSC}$ and $0.5 \%$ SDS. Filters were then exposed to Kodak XAR5 film (Eastman Kodak, Rochester, $\mathrm{NY}$ ) for 1-12 d, and the band intensity was quantitated using a computerassisted image analysis system using the film exposure with the optimal densities of each band (i.e., within the linear range) (MCID; Imaging Research, Inc., St. Catharines, Ontario). To control for variability in loading and transfer, all membranes were probed with a 700 bp human $\beta$-actin probe. $\beta$-Actin mRNA levels appear to remain constant throughout the hibernation cycle based on our comparisons of total RNA loaded and $\beta$-actin band density of hundreds of samples from different stages of hibernation. Multiple probings of the same Northern filters were carefully monitored to ensure that no residual radioactivity from previous probes remained and that no other degradation of the filters was apparent.

Most hybridization probes of the known genes used in this study were derived from gel-isolated fragments of rat, mouse, or human cDNA sequences that are well conserved across mammalian species. Three cDNAs, F1-ATPase, RNA poly(A) polymerase, and NADH-ubiquinone oxireductase, were isolated from a closely related species of squirrel, Spermophilus richardsonii (Srere, 1995). The 29 ddPCR fragments were unknown cDNA sequences from Spermophilus lateralis. The precise regions of each cDNA used to probe for c-fos, junB, c-jun, junD, NGFI-A, enkephalin, somatostatin, GAD65, GAD67, $\beta$-actin, and GAP43 were described previously (O'Hara et al., 1989, 1994, 1995, 1997). For other genes, cDNAs containing all or most of the coding sequence were used and can be found in PGD2 synthase (Urade et al., 1993), SD464 (Rhyner et al., 1990), cyclophilin (Hasel et al., 1991), and histidine decarboxylase (Joseph et al., 1990).

$d d P C R$. All ddPCR experiments were performed with total RNA derived from the cerebral cortex of Spermophilus lateralis to have sufficient RNA for both ddPCR and for subsequent Northern analyses to test putative positives. RNA derived from squirrels killed on day 4 of torpor (hibernation day 4), during the interbout euthermic period (winter euthermia), or during the summer active phase (summer euthermia) were compared. RNA samples were DNase treated and phenol-chloroform

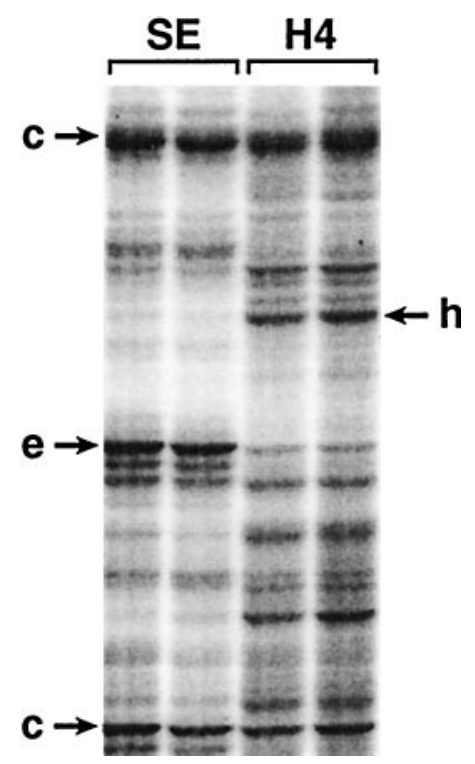

Figure 2. ddPCR. Samples of total RNA were isolated from ground squirrel cortex during summer euthermia and hibernation day 4 . The isolated RNAs were used as templates in duplicate to generate cDNA fragments, which were then amplified by PCR and separated on polyacrylamide gels. $S E$, Summer euthermic; $H 4$, hibernation day $4 ; c \rightarrow$, bands that appear to remain constant across the two conditions; $e \rightarrow$, bands that appear to be more abundant during euthermia; $\leftarrow h$, bands that appear to be more abundant during hibernation. 
A c-fos SE WE EN H1 H5 AR c-jun

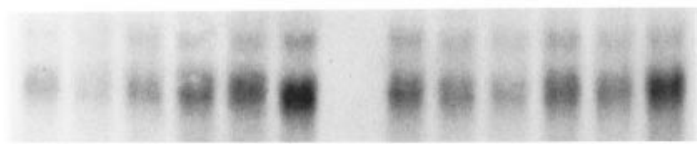
SE WE EN H1 H5 AR SE WE EN H1 H5 AR junB

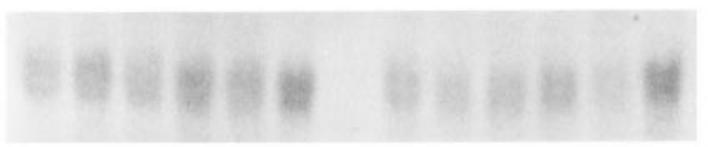
SE WE EN H1 H5 AR SE WE EN H1 H5 AR junD

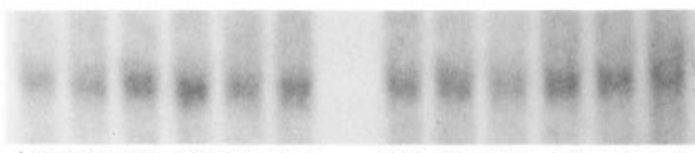

SE WE EN H1 H5 AR
SE WE EN H1 H5 AR

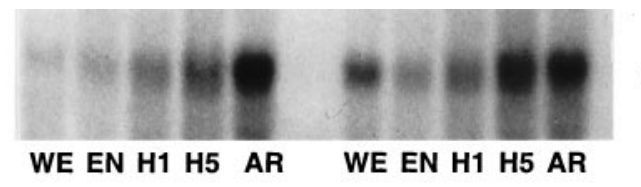

- 2.2kb

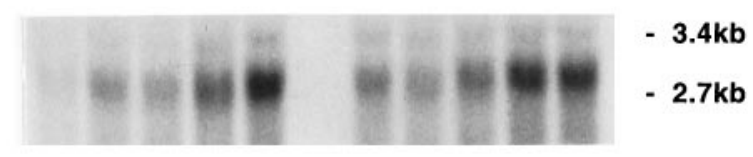

WE EN H1 H5 AR WE EN H1 H5 AR

$-1.8 \mathrm{~kb}$
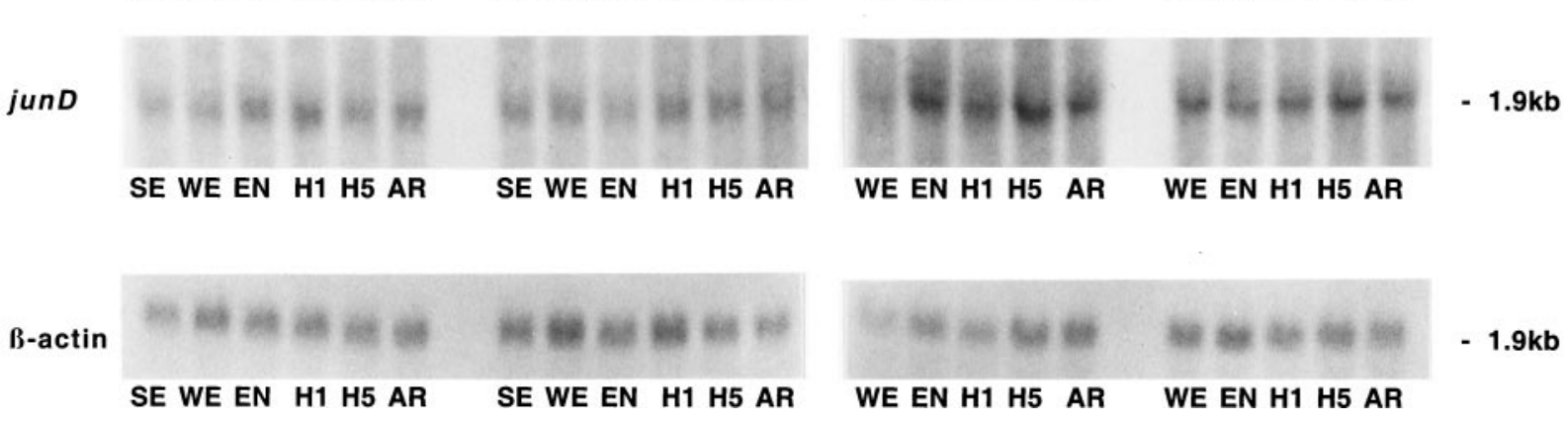

Figure 3. Expression of IEGs in hypothalamus across hibernation. A, Autoradiographs of Northern blots of total RNA (20 $\mu \mathrm{g} / \mathrm{lane}$ ) isolated from hypothalamus of ground squirrels killed during different phases of the hibernation cycle and hybridized to [ $\left.{ }^{32} \mathrm{P}\right]$-labeled $\mathrm{c}$-fos, $\mathrm{c}$-jun, junB, and junD cDNA probes. Sizes of mRNAs are shown to the right in kilobases. Note the increasing levels of both c-fos and c-jun mRNA during late torpor and then peaking during arousal relative to other phases of hibernation. The c-fos probing on the left and right were done at different times with different specific activity and total counts per minutes and do not represent differences in c-fos expression between these groups. Each blot was normalized internally for statistical analyses shown in the histograms in $B . S E$, Summer euthermic; $W E$, winter euthermic; $E N$, entrance; $H 1$, hibernation day $1 ; H 5$, hibernation day 5; $A R$, arousal. $\beta$-actin mRNA serves as a control for RNA loading in each lane. $n=4$ for each condition during the hibernation season, and $n=$ 2 for summer euthermia $(S E)$. B, Quantitation of the relative mRNA levels are shown based on band density of the autoradiograms in $A$. Each graph displays means \pm SEs. To control for variability in loading and transfer, all data are presented relative to $\beta$-actin, whose expression remains constant throughout the hibernation cycle relative to total RNA and total mRNA (data not shown). mRNA levels of c-fos, c-jun, and junB during arousal (AR) are significantly elevated relative to baseline winter euthermic levels. ${ }^{*} p<0.01$.

extracted before reverse transcription. The reverse transcription reaction was performed using $0.2 \mu \mathrm{g}$ of DNA-free RNA in a $20 \mu \mathrm{l}$ volume containing $20 \mathrm{~mm}$ dNTPs, $125 \mathrm{~mm}$ Tris-HCl, pH 8.3, $188 \mathrm{~mm} \mathrm{KCl,} 7.5$ $\mathrm{mM} \mathrm{MgCl}_{2}, 25 \mathrm{mM}$ DTT, and $100 \mathrm{U}$ of MMLV reverse transcriptase in separate reactions containing $0.2 \mathrm{~mm} 3^{\prime}$ primers anchored to subsets of the RNA pool by single base changes $\left[\right.$ poly- $\mathrm{dT}_{11} \mathrm{~A}$, poly- $\mathrm{dT}_{11} \mathrm{G}$, poly$\mathrm{dT}_{11} \mathrm{C}$, and poly-dT $\mathrm{T}_{11} \mathrm{~T}$ supplied in kit form (GenHunter Corp., Nashville, TN)]. Reactions were performd at $37^{\circ} \mathrm{C}$ for $1 \mathrm{hr}$ after an initial $65^{\circ} \mathrm{C}$ denaturation step to allow annealing of the primers. One-tenth of the reverse transcription reaction product from each reaction was used in each subsequent PCR amplification using the original $3^{\prime}$ primer, in conjunction with random 13 -mers as $5^{\prime}$ primers (GenHunter Corp.). PCR reactions contained $2 \mathrm{~mm}$ each $3^{\prime}$ and $5^{\prime}$ primers, $25 \mathrm{~mm}$ dNTPs, 2 $\mu$ of reverse transcription reaction product, PCR buffer (GenHunter Corp. $),\left[\alpha^{-}{ }^{35} \mathrm{~S}\right] \mathrm{dATP}(1200 \mathrm{Ci} / \mathrm{mmol})$, and Amplitaq DNA polymerase (Perkin-Elmer, Emeryville, CA). PCR conditions were $94^{\circ} \mathrm{C}$ for $30 \mathrm{sec}$, $40^{\circ} \mathrm{C}$ for $2 \mathrm{~min}$, and $72^{\circ} \mathrm{C}$ for $30 \mathrm{sec}$, each for 40 cycles. PCR products were analyzed on $5 \%$ nondenaturing polyacrylamide gels, and banding patterns were compared between conditions. Forty-five primer combinations were used, and $\sim 100$ bands could be visualized with each primer set. Therefore, in theory, $\sim 4500$ mRNA transcripts were compared between deep hibernation and euthermic conditions, although there is likely to be some redundant cDNAs amplified by different primer sets. Most analyses compared summer euthermia versus deep hibernation.

Data analysis. The resultant data were analyzed by one-way ANOVA. Wherever post hoc tests were indicated, the data were analyzed by both Fisher's protected least significance difference test and Scheffe's $F$ test; the results presented are only those in which these tests agree as to significance.

\section{RESULTS}

\section{Changes in mRNA expression assayed by ddPCR}

Samples of total RNA isolated from ground squirrel cortex during summer euthermia, the winter interbout euthermic period, and the fourth day of torpor, were used as templates to generate cDNA fragments, which were then amplified by PCR and separated on polyacrylamide gels. Differences in expression between test conditions were visualized by autoradiography of ${ }^{35} \mathrm{~S}$-labeled bands (Fig. 2). Most comparisons were between summer euthermia and winter torpor (day 4 of a single hibernation bout) because these two states were hypothesized to have the most differences in gene expression. The initial screen of 4500 transcripts (in theory) produced 29 bands, indicating differences between these two states. These bands were cut out and reamplified for verification by Northern analysis on blots prepared from the initial RNA samples. All 29 probes produced distinctive bands, but none of the 29 putative differences in expression were significant when tested on Northern blots containing samples of summer euthermia and winter hibernation (data not shown). Therefore, no enrichment of hibernation-responsive genes was achieved by this method. However, the fact that 29 of 29 selected cDNAs failed to show any significant changes in steady-state mRNA 

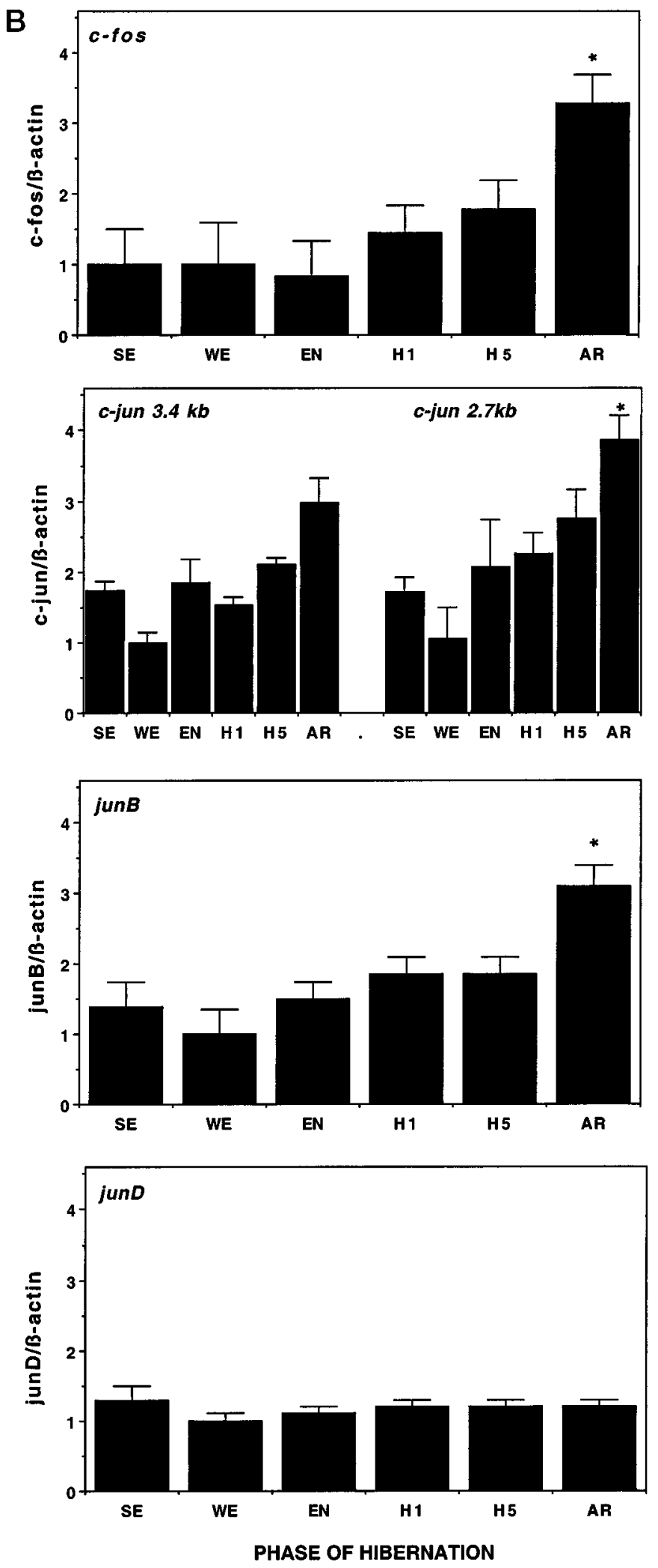

Figure 3 Continued. levels suggests that the majority of mRNAs do not dramatically change in abundance across these conditions.

\section{Changes in mRNAs assayed by Northern analysis}

In contrast to the ddPCR method, Northern analysis of selected, well characterized genes was used as a directed approach to test variability within the hibernation cycle. All cDNA probes produced one or two distinctive bands, with sizes, intensity (reflecting abundance), and expression patterns consistent with known data in the mouse, rat, and human. Some Northern analyses were run with RNA derived from multiple species to further support that each cDNA probe was recognizing its homolog in the squirrel.

Differential expression among IEG family members was observed within the hypothalamus across the hibernation cycle. Whereas c-fos, junB, and c-Jun mRNAs appear to increase during torpor and peak during arousal in hypothalamus, junD remains constant (Fig. 3). The increase in expression of c-fos and c-Jun during arousal is not confined to the hypothalamus but occurs in other brain regions, such as the cortex (Fig. 4), and in almost every other brain region examined, including thalamus, basal forebrain, septum, hippocampus, striatum, midbrain, cerebellum, pons, and medulla (our unpublished observations). In a peripheral tissue, such as brown fat (Fig. 5), c-fos expression is dramatically higher during arousal but is virtually undetectable at other times and does not exhibit the trend toward higher expression during the latter part of torpor characteristic of hypothalamus (Fig. 3). Liver and spleen also exhibit sharp rises in c-fos mRNA during arousal but have somewhat higher basal levels (our unpublished observations). To investigate the time course of c-fos expression in the hypothalamus in finer detail, samples were taken at additional time points. Figure 6 confirms that the peak in c-fos expression occurs during arousal from torpor, with a return to basal levels within $2 \mathrm{hr}$ after arousal.

In contrast to the IEGs, two neuropeptide mRNAs known to be expressed in hypothalamus, somatostatin and enkephalin, did not undergo significant changes across the hibernation cycle (Fig. 7), despite previous evidence for changes in peptide or mRNA levels (Nurnberger et al., 1991, 1997).

Figure 8 illustrates that PGD2 synthase mRNA varies significantly over the hibernation cycle, declining sharply in the hypothalamus after many days of hibernation, and returning to its former level during arousal, whereas the cortex and basal forebrain both show a more modest decline that does not quite reach statistical significance.

Several other genes were examined, including GAD65, GAD67, histidine decarboxylase, SD464, GAP43, cyclophilin, and three housekeeping genes whose expression in the liver varies across the hibernation season (Srere, 1995). No significant changes in steady-state mRNA levels were found in the brain for any of these genes across phases of hibernation. These genes, along with those described above, are summarized in Table 1. Only some IEGs and PGD2 synthase were found to exhibit significant differences in steady-state mRNA levels across different phases of hibernation. For most genes, the within-group variation was modest, and differences in mRNA abundance greater than twofold would usually be detected as significant.

\section{DISCUSSION}

We have investigated changes in mRNA levels in the brain from a variety of genes across phases of hibernation in the goldenmantled ground squirrel. Considerable evidence suggests that the 


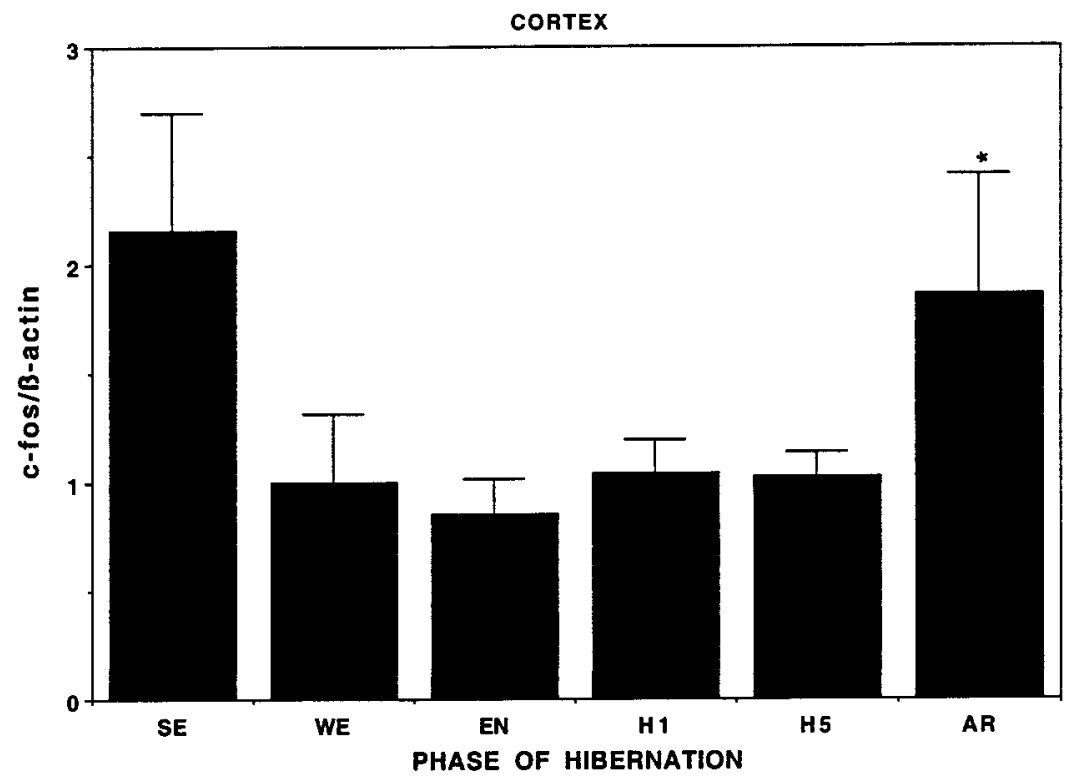

Figure 4. Quantitation of relative c-fos mRNA levels in cortex. Graphic representation of c-fos mRNA levels in the cerebral cortex across different hibernation states as shown with hypothalamus in this and Figure 3. $n=4$ for $W E, E N$, $H 1, H 5$, and $A R . n=2$ for $S E$. The cortical samples were derived from the same animals as hypothalamus. Abbreviations as in Figure 3. Note that c-fos mRNA levels are again significantly elevated in $A R$ relative to $W E, E N, H 1$, and $H 5$. ${ }^{*} p<0.05$. $S E$ levels of c-fos mRNA also appear to be elevated but could not be supported statistically because $n=2$. brain plays a major role in regulating the extreme changes in body temperature, metabolism, and other physiological variables that accompany hibernation (Mihailovic, 1972; Heller and Colliver, 1974; Heller, 1979; Dark et al., 1990). The hypothalamus in particular appears to play a critical role in both the entrance to and arousal from each hibernation bout (Heller, 1979; Kilduff et al., 1990) and was studied most extensively in this paper. The cerebral cortex was also of interest because this brain region has provided measures of arousal state variation across hibernation using conventional EEG monitoring (Mihailovic, 1972; Walker et al., 1977), and suppression of metabolic activity in this structure has been implicated in the entrance to hibernation (Kilduff et al., 1990). In general, other brain regions, such as hippocampus and basal forebrain, were similar to cortex for all of the mRNAs studied (unpublished data). Brain regions aside from hypothalamus, cortex, hippocampus, and basal forebrain were studied in only a few samples because there did not appear to be any dramatic regional differences. The hypothalamus, as the prime region of focus, did display some potentially unique characteristics, such as increases in IEG mRNAs as each torpor bout progressed, as opposed to increases only at arousal. The hypothalamus also displayed the only significant change in PGD2
mRNA levels and the most rapid rise in PGD2 mRNA during arousal.

Across all mRNAs studied, we were somewhat surprised by the constancy of mRNA levels given the extreme physiological changes that accompany hibernation. Because the ddPCR compared summer euthermic versus deep torpor, it could have identified genes that regulate the hibernation process, genes that respond to the seasonal changes, or genes that change with body temperature, metabolism, etc. The ddPCR method can produce false positives (Debouck, 1995), and that appears to have occurred in this study. Nonetheless, these experiments did provide a sample of 29 different cDNAs. The fact that none of the ddPCR products and only one known gene examined, PGD2 synthase, declined significantly during torpor may be particularly worth noting. At the low body temperatures achieved during hibernation $\left(8^{\circ} \mathrm{C}\right.$ or less under our ambient conditions of $\left.5^{\circ} \mathrm{C}\right)$, it seemed likely that RNA transcription might virtually cease, and all RNAs would either be maintained or would decrease in abundance. In fact, such a decline might explain the mystery of periodic arousals throughout the hibernation season, which are metabolically costly and limit the energy conservation achieved (Lyman et al., 1982). However, we found no evidence for a general decline in total c-fos

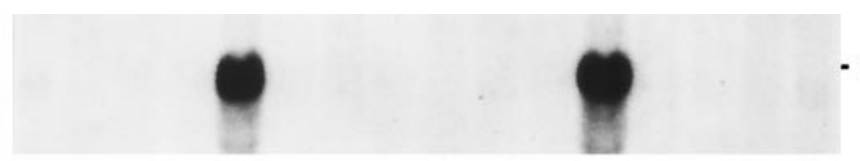

P9 EN H1 h5 AR P2 P5 P9 EN H1 h5 AR P2 P5 P9 SE

junB

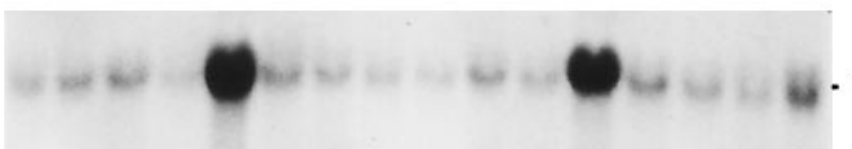

P9 EN H1 h5 AR P2 P5 P9 EN H1 H5 AR P2 P5 P9 SE B-actin

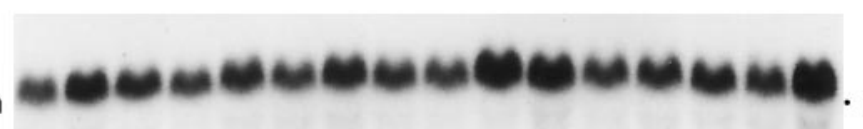

P9 EN H1 h5 AR P2 P5 P9 EN H1 h5 AR P2 P5 P9 SE

2.2kb

$1.8 \mathrm{~kb}$

$1.9 \mathrm{~kb}$
Figure 5. Expression of c-fos and junB in brown fat. Autoradiographs of Northern blots of total RNA (20 $\mu \mathrm{g} / \mathrm{lane})$ isolated from brown adipose tissue of squirrels at different phases of the hibernation cycle. Note the extremely low basal level of c-fos mRNA and the very strong induction during arousal. $P 2,2 \mathrm{hr}$ after arousal; $P 5,5 \mathrm{hr}$ after arousal; $P 9,9 \mathrm{hr}$ after arousal (from a $\mathrm{T}_{\mathrm{b}}$ of $20^{\circ} \mathrm{C}$ ); $S E$, summer euthermic; $E N$, entrance; $H 1$, hibernation day $1 ; H 5$, hibernation day 5 ; $A R$, arousal. $\beta$-actin mRNA serves as a control to assess RNA loading in each lane. 


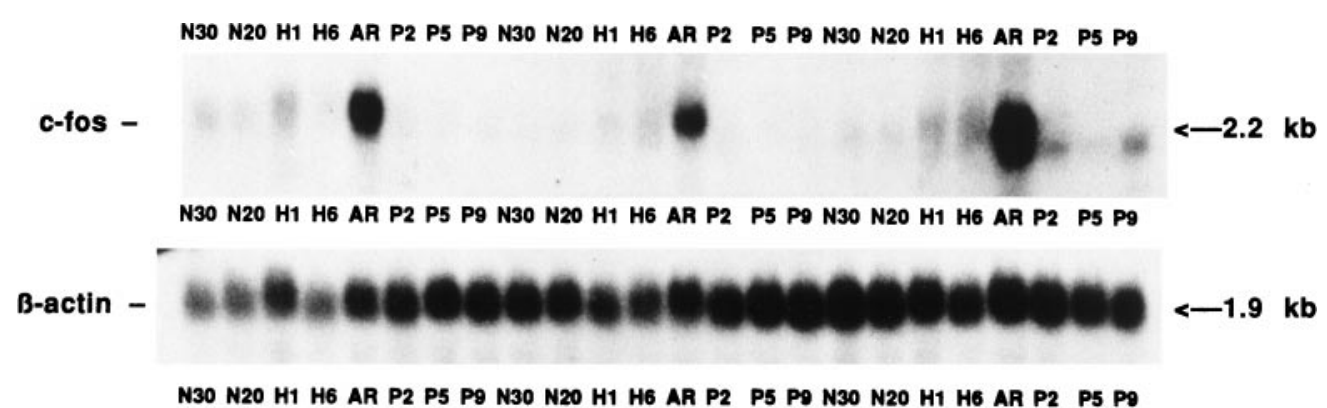

Figure 6. Rapid return of c-fos mRNA levels after arousal. Autoradiographs of Northern blots of total RNA $(20 \mu \mathrm{g} /$ lane) isolated from hypothalamus of ground squirrels killed during different phases of the hibernation cycle as in Figure 3, with the addition of several well defined postarousal time points and one additional entrance time point $(N 30) . N 30$ is early entrance to torpor $\left(\mathrm{T}_{\mathrm{b}}\right.$ of $\left.30^{\circ} \mathrm{C}\right)$, and $N 20$ is midentrance $\left(\mathrm{T}_{\mathrm{b}}\right.$ of $20^{\circ} \mathrm{C}$ ), the same as $E N$ in other figures. Note the increasing amount of c-fos mRNA during torpor and the high peak during arousal as in Figure 3, and then the rapid return to basal levels after arousal. Levels of c-fos mRNA during arousal are significantly elevated over all other phases; ${ }^{*} p<0.01 . n=3$ for each condition. Other abbreviations as in Figures $3-5$.

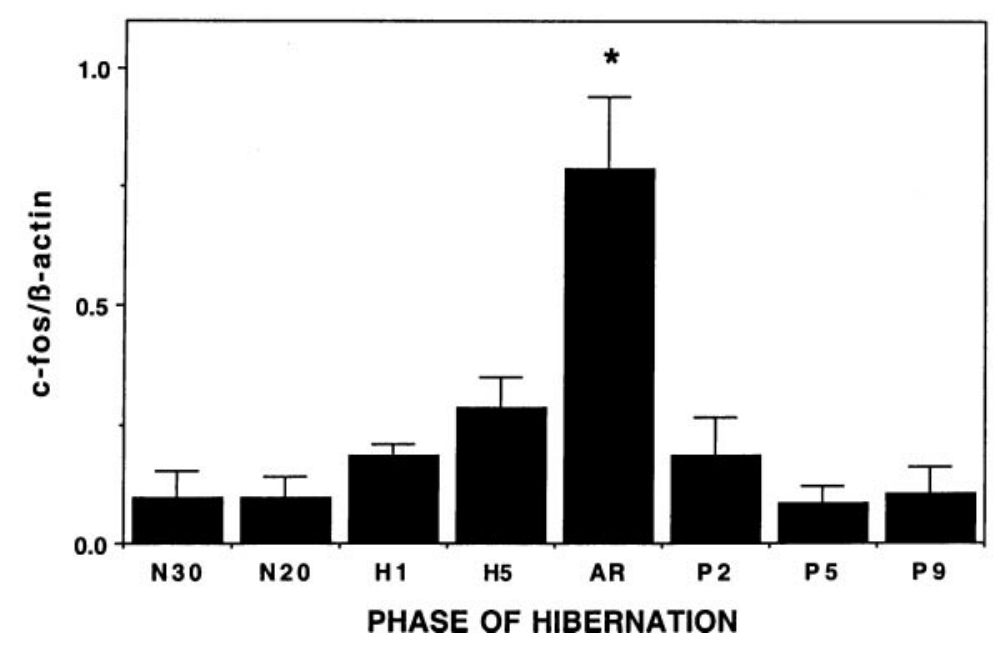

Table 1. Changes in mRNA levels across the hibernation cycle

Immediate early genes

c-fos

c-jun

junB

junD

NGFI-A

Neuropeptides

somatostatin

enkephalin

Prostaglandin D2 synthase

Sleep deprivation cDNA 464

Glutamic acid decarboxylases

GAD65

GAD67

Histidine decarboxylase

GAP 43

Control genes

$\beta$-actin

Cyclophillin

Housekeeping genes reported to change in liver (Srere, 1995)

F1-ATPase

RNA poly(A) polymerase

NADH-ubiquninone oxireductase

29 ddPCR probes $\uparrow \mathrm{AR}$ (multiple brain regions)

$\uparrow \mathrm{AR}$ (multiple brain regions)

$\uparrow \mathrm{AR}$ (multiple brain regions)

$\leftarrow \mathrm{NSC} \rightarrow$ (multiple brain regions)

$\uparrow \mathrm{AR}$ (multiple brain regions)

$\leftarrow \mathrm{NSC} \rightarrow$ (multiple brain regions)

$\leftarrow \mathrm{NSC} \rightarrow$ (multiple brain regions)

$\downarrow$ H5 (hypothalamus)

$\leftarrow \mathrm{NSC} \rightarrow$ (multiple brain regions)

$\leftarrow \mathrm{NSC} \rightarrow$ (hypothalamus)

$\leftarrow \mathrm{NSC} \rightarrow$ (hypothalamus)

$\leftarrow \mathrm{NSC} \rightarrow$ (hypothalamus)

$\leftarrow \mathrm{NSC} \rightarrow$ (cortex, hippocampus)

$\leftarrow \mathrm{NSC} \rightarrow$ (multiple brain regions)

$\leftarrow \mathrm{NSC} \rightarrow$ (multiple brain regions)

$\leftarrow \mathrm{NSC} \rightarrow$ (cortex)

$\leftarrow \mathrm{NSC} \rightarrow$ (multiple brain regions)

$\leftarrow \mathrm{NSC} \rightarrow$ (multiple brain regions)

$\leftarrow \mathrm{NSC} \rightarrow$ (cortex)
RNA yields, mRNA yields, or specific mRNAs tested, consistent with recent work in some peripheral tissues (Srere et al., 1992; Carey and Martin, 1996). Instead, some mRNAs (e.g., c-fos, c-jun) in our study appear to increase in the brain during torpor, although these changes do not reach statistical significance until the arousal phase. In peripheral tissues, a small number of $\mathrm{mR}$ NAs and proteins have been found to vary between torpor and euthermia, with examples of both increasing (Srere et al., 1992; Wilson et al., 1992; Andrews et al., 1998; Gorham et al., 1998) and decreasing expression (Kondo and Kondo, 1992; Takamatsu et al., 1997), which are concordant at the mRNA and protein levels in all cases examined. None of these other studies, however, focus on the detailed time points across hibernation bouts, especially the dramatic periods of arousal from and entrance to hibernation.

In this report, we found that basal levels of IEG mRNAs were clearly higher in the brain than in brown fat and other peripheral tissues (Figs. 3-5; our unpublished observations). These data strengthen the argument that the brain is relatively more active during hibernation than many peripheral tissues. Furthermore, because there does not appear to be a general decline in most mRNAs (which might appear as relative increases in some genes), it is extremely likely that substantial new transcription of some genes does take place during arousal from hibernation (as indicated by c-fos induction) and that, in hypothalamus, this may occur even at the coldest body temperatures during torpor. It does not seem likely that the large increases in IEG mRNAs could occur only by changes in mRNA stability. In addition, our data may be relevant to the fact that animals are increasingly responsive to stimuli as each bout of hibernation progresses (Beckman and Stanton, 1976), suggesting the possibility of increasing CNS function and the need for new mRNA synthesis. 


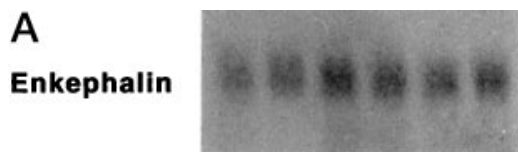

SE WE EN H1 H5 AR

Somatostatin

SE WE EN H1 H5 AR

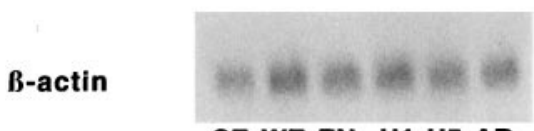

SE WE EN H1 H5 AR

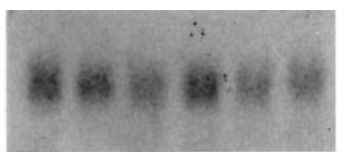

SE WE EN H1 H5 AR

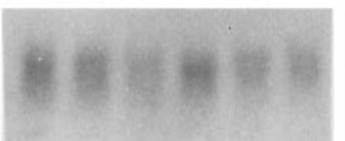

SE WE EN H1 H5 AR

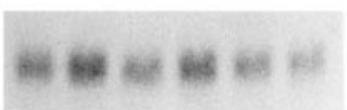

SE WE EN H1 H5 AR

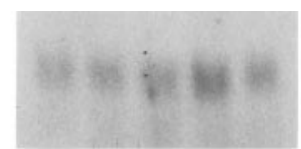

WE EN H1 H5 AR

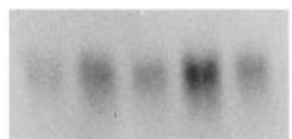

WE EN H1 H5 AR

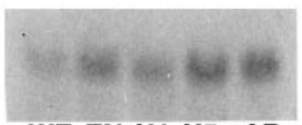

WE EN H1 H5 AR

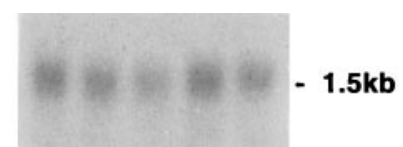

WE EN H1 H5 AR

$0.7 \mathrm{~kb}$
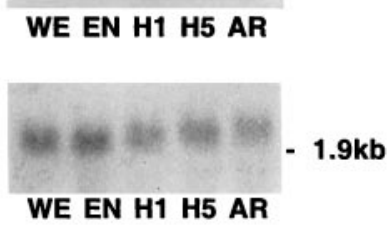

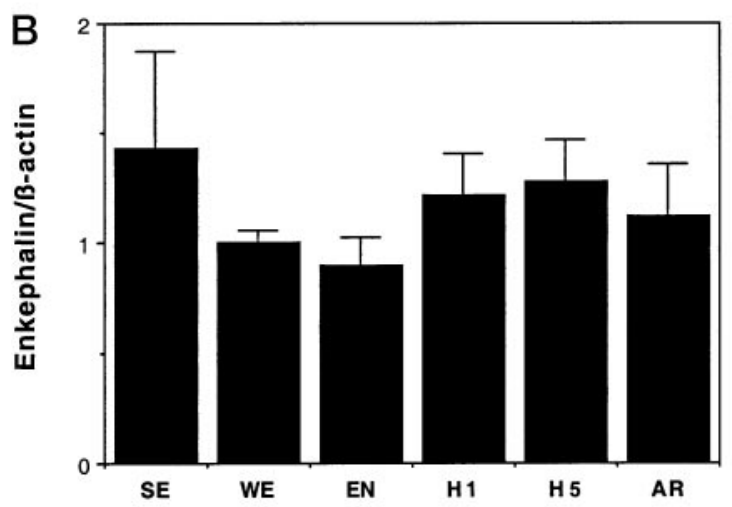

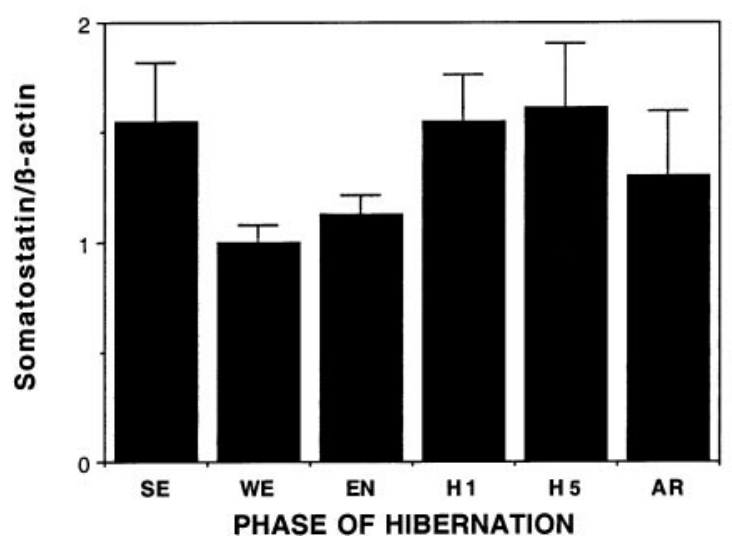

Figure 7. Somatostatin and enkephalin mRNA levels show no change across hibernation. $A$, Autoradiographs of Northern blots of total RNA ( $20 \mu \mathrm{g} / \mathrm{lane})$ isolated from the hypothalamus of ground squirrels using the same filters as in Figure 3 and hybridized to $\left[{ }^{32} \mathrm{P}\right]$-labeled somatostatin and enkephalin cDNA probes. Abbreviations as in Figure 3. B, Quantitation of relative mRNA levels of somatostatin and enkephalin across hibernation. Graphic representation of band intensity was quantitated by optical density. To control for variability in loading and transfer, all data are presented relative to $\beta$-actin as in other figures. No significant change for either mRNA occurs across these conditions.
Our inability to detect significant changes in enkephalin or somatostatin mRNA, despite changes at the protein level (Nurnberger et al., 1991, 1997), suggests regulation at steps other than transcription, although it is possible that our nonsignificant increase in enkephalin mRNA does underlie the significant differences at the protein level or that changes in enkephalin occur in a relatively small percentage of enkephalin neurons. Because of individual variability, sample size, and technical limitations in the quantification of mRNA levels, our study was designed to detect relatively large changes in gene expression of greater than twofold. There are probably many important smaller changes in gene expression that, in concert, play an important or even dominant role. In fact, the small number of genes we have found with large changes makes this possibility likely.

In contrast to the majority of genes, IEG expression can vary widely across experimental conditions (Bartel et al., 1989; Sheng and Greenberg, 1990; Morgan and Curran, 1991; Sutin and Kilduff, 1992), as we found to occur across hibernation. This is especially apparent in brown fat (Fig. 5) in which levels are barely detectable but rise dramatically during arousal. Although c-fos levels in the brain also exhibit this induction, basal levels are much higher and, as noted above, appear to increase late in torpor in some brain regions, such as hypothalamus. Both the higher basal level and the possible earlier induction in the hypothalamus suggest a central role in regulatory control. We have found previously that the suprachiasmatic nucleus of the hypothalamus undergoes a dramatic induction of c-fos mRNA during the arousal phase (Bitting et al., 1994); however, the in situ methodology used was not sensitive enough to measure c-fos in other brain regions. Our current study shows that c-fos induction during arousal occurs throughout the brain and in most peripheral tissues as well, although the hypothalamus continues to stand out as 

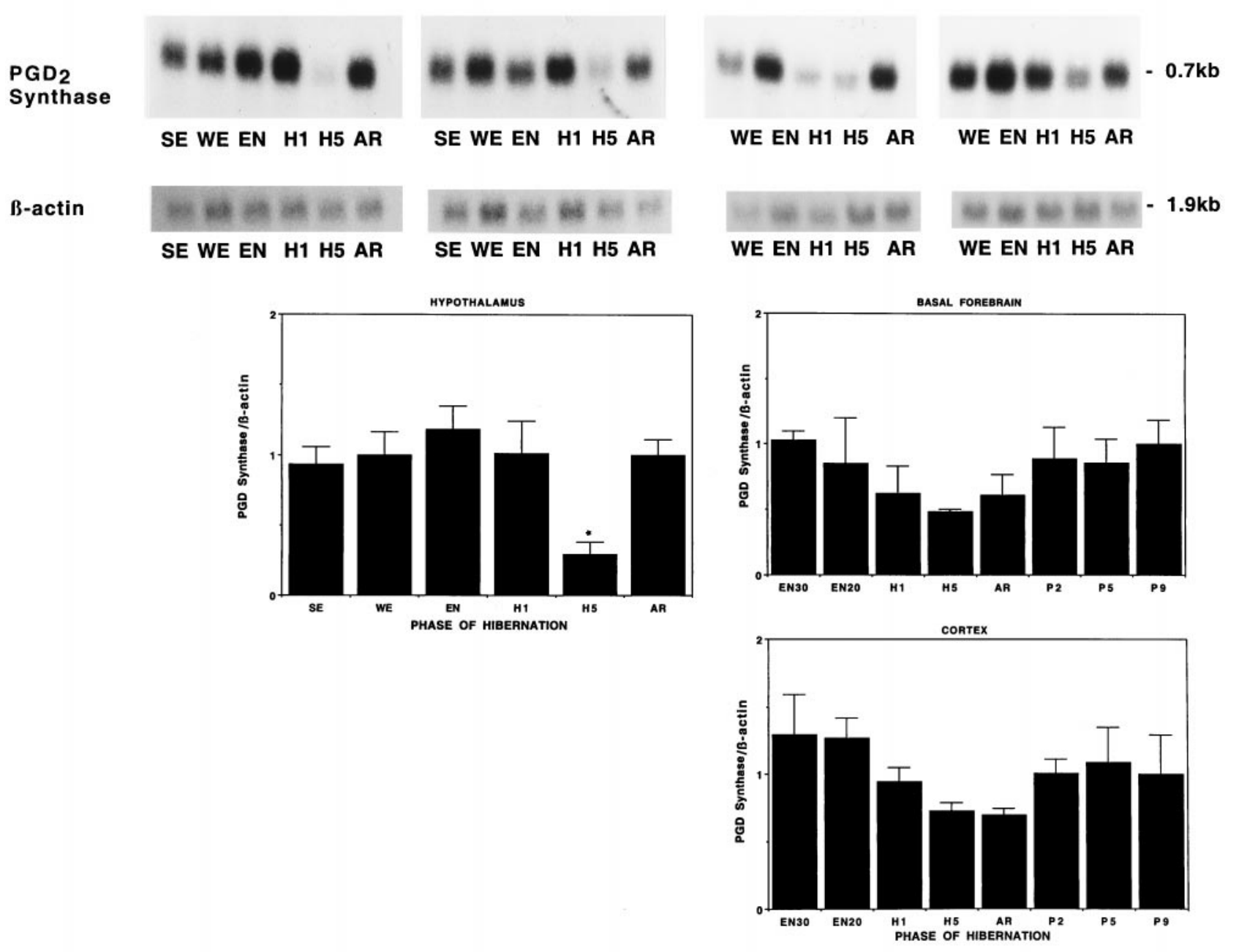

Figure 8. PGD2 synthase mRNA declines during torpor. Autoradiographs of Northern blots of total RNA (20 $\mu \mathrm{g} /$ lane) isolated from hypothalamus along with graphic representations of hypothalamus, cerebral cortex, and basal forebrain of ground squirrels killed during different phases of hibernation cycle and hybridized to a [ $\left.{ }^{32} \mathrm{P}\right]$-labeled PGD2 synthase cDNA probe. Note the decreased level of PGD2 synthase mRNA during late torpor in the hypothalamus relative to all other conditions; ${ }^{*} p<0.05$. The lower levels of PGD2 synthase mRNA in the cortex and basal forebrain during late torpor and arousal do not quite reach statistical significance. Filters for the hypothalamus are the same as used previously, and the cortical and basal forebrain samples are from the same animals as the hypothalamus shown in Figure 6.

the most dynamic brain region (both in terms of IEG and PGD2 synthase mRNAs). The cerebral cortex has a relatively high basal level of c-fos but shows no increase in late torpor. Aside from hibernation, c-fos levels in the cortex correlate well with activity and sleep (Grassi-Zucconi et al., 1993; Pompeiano et al., 1994; O'Hara et al., 1997). Therefore, the higher levels of c-fos mRNA in the cortex of summer active animals (Fig. 4) may reflect higher activity of the squirrels at this time, although because of the availability of only two summer active animals, this difference could not be established statistically. The rapid decline of c-fos mRNA in the hypothalamus after arousal may also be in part caused by sleep, because the initial period of interbout euthermia almost invariably contains very deep sleep (Daan et al., 1991; Trachsel et al., 1991; Kilduff et al., 1993). Because IEGs are transcription factors, we are currently investigating this postarousal period in greater detail to determine which genes may be subsequently activated or inactivated. An important determining factor in target gene activation by FOS/JUN heterodimers is which JUN partner is paired with FOS (Ryseck and Bravo, 1991). Therefore, it is relevant to note that c-jun and junB both increase along with c-fos mRNA, but junD remains constant. In studies of IEG expression in the rat across circadian time and arousal states, c-fos and junB both increase with periods of high locomotor activity, whereas junD and c-jun remain invariant (O'Hara et al., 1993, 1997). In contrast, squirrels appear to use c-jun induction together with c-fos and junB (O’Hara et al., 1997) (Fig. 3).

As with the rapid decline in c-fos mRNA after arousal, the change in PGD2 synthase mRNA levels may also reflect relationships between hibernation and sleep (Heller, 1979; Kilduff et al., 1993). Prostaglandins are locally acting hormones produced from metabolism of arachidonic acid by the cyclooxygenase pathway. PGD2 both induces sleep (Hayaishi, 1997; Ram et al., 1997) and reduces somatosensory pain perception (Minami et al., 1996). PGD2 circulates within the CNS in the ventricular system and subarachnoid space and is produced primarily by choroid plexus and leptomeninges, and to a lesser extent by glia and neurons (Urade et al., 1993). We do not believe any of our samples contain choroid plexus or leptomeninges; therefore, we are most likely measuring the lower levels of expression in the neurons and glia of each brain region. PGD2 has also been shown to increase 
seasonally in the Asian chipmunk, another mammalian hibernator (Takahata et al., 1996). Interestingly, not only is there a decline in PGD2 synthase mRNA during late torpor but a subsequent rapid return to high expression during arousal in the hypothalamus and during interbout euthermia in the basal forebrain and cortex. The basal forebrain is the most responsive brain region with respect to the sleep promoting ability of PGD2 (Matsumura et al., 1994), and this may therefore relate to the hypersomnia of the postarousal period (Trachsel et al., 1991).

In summary, our findings suggest that only a small percentage of mRNAs undergo large changes in steady-state levels in the brain across the hibernation cycle. The mRNAs identified that do undergo large changes, IEGs and PGD2 synthase, seem likely to play important roles in the extreme physiological and arousal state changes that accompany individual hibernation bouts.

\section{REFERENCES}

Andrews MT, Squire TL, Bowen CM, Rollins MB (1998) Lowtemperature carbon utilization is regulated by novel gene activity in the heart of a hibernating mammal. Proc Natl Acad Sci USA 95:8392-8397.

Bartel D, Sheng M, Lau LF, Greenberg ME (1989) Growth factors and membrane depolarization activate distinct programs of early response gene expression. Genes Dev 3:304-313.

Beckman AL, Llados-Eckman C (1985) Antagonism of brain opioid peptide action reduces hibernation bout duration. Brain Res 328:201-205.

Beckman AL, Stanton TL (1976) Changes in CNS responsiveness during hibernation. Am J Physiol 231:810-816.

Beckman AL, Llados-Eckman C, Tanton TL, Adler MW (1981) Physical dependence on morphine fails to develop during the hibernation state. Science 212:1527-1529.

Beckman AL, Dean RR, Wamsley JK (1986) Hippocampal and cortical opioid receptor binding: changes related to the hibernation state. Brain Res 386:223-231.

Benowitz L, Routtenberg A (1987) A membrane phosphoprotein associated with neural development, axonal regeneration, phospholipid metabolism, and synaptic plasticity. Trends Neurosci 10:527-532.

Bitting L, Sutin EL, Watson FL, Leard LE, O'Hara BF, Heller HC, Kilduff TS (1994) C-fos mRNA increases in the ground squirrel suprachiasmatic nucleus during arousal from hibernation. Neurosci Lett 165:117-121.

Carey HV, Martin SL (1996) Perservation of intestinal gene expression during hibernation. Am J Physiol 271:G804-G813.

Daan S, Barnes BM, Strijkstra AM (1991) Warming up for sleep? Ground squirrels sleep during arousals from hibernation. Neurosci Lett 128:265-268.

Dark J, Kilduff TS, Heller HC, Licht P, Zucker I (1990) Suprachiasmatic nuclei influence hibernation rhythms of golden-mantled ground squirrels. Brain Res 509:111-118.

Debouck C (1995) Differential display or differential dismay? Curr Opin Biotechnol 6:597-599.

Erlander M, Tillakaratne N, Feldblum S, Patel N, Tobin A (1991) Two genes encode distinct decarboxylases. Neuron 7:91-100.

Gorham DA, Bretscher A, Carey HV (1998) Hibernation induces expression of moesin in intestinal epithelial cells. Cryobiology $37: 146-154$

Grahn DA, Miller JD, Houng VS, Heller HC (1994) Persistence of circadian rhythmicity in hibernating ground squirrels. Am J Physiol 266:R1251-R1258.

Grassi-Zucconi G, Menegazzi M, De Prati AC, Bassetti A, Montagnese P, Mandile P, Cosi C, Bentivoglio M (1993) c-fos mRNA is spontaneously induced in the rat brain during the activity period of the circadian cycle. Eur J Neurosci 5:1071-1078.

Hasel KW, Glass JR, Godbout M, Sutcliffe JG (1991) An endoplasmic reticulum-specific cyclophilin. Mol Cell Biol 11:3484-3491.

Hayaishi O (1997) Prostaglandin D synthase, $\beta$-trace and sleep. Adv Exp Med Biol 433:347-350.

Heller HC (1979) Hibernation: neural aspects. Annu Rev Physiol 41:305-321.

Heller HC, Colliver GW (1974) CNS regulation of body temperature during hibernation. Am J Physiol 227:583-589.

Heller HC, Florant GL, Glotzbach SF, Walker JM, Berger RJ (1978)
Sleep and torpor-homologous adaptations for energy conservation. In: Dormancy and developmental arrest (Clutter M, ed), pp 269-296. New York: Academic.

Joseph DR, Sullivan PM, Wang YM, Kozak C, Fenstermacher DA, Behrendsen ME, Zahnow CA (1990) Characterization and expression of the complementary DNA encoding rat histidine decarboxylase. Proc Natl Acad Sci USA 87:733-737.

Kilduff TS, Miller JD, Radeke CM, Sharp FR, Heller HC (1990) $\left[{ }^{14}\right.$ C]2deoxyglucose uptake in ground squirrel brain during entrance to and arousal from hibernation. J Neurosci 10:2463-2475.

Kilduff TS, Krilowicz B, Milsom W, Trachsel L, Wang LCH (1993) Sleep and mammalian hibernation: homolgous adaptations and homologous processes? Sleep 16:372-386.

Kondo N, Kondo J (1992) Identification of novel blood proteins specific for mammalian hibernation. J Biol Chem 267:473-478.

Krilowicz BL, Glotzbach SF, Heller HC (1988) Neuronal activity during sleep and complete bouts of hibernation. Am J Physiol 255:R1008R1019.

Lyman CP, Willis JS, Malan A, Wang LC (1982) Hibernation and torpor in mammals and birds, p 317. New York: Academic.

Matsumura H, Nakajima T, Osaka T, Satoh S, Kawase K, Kubo E, Kantha SS, Kasahara K, Hayaishi O (1994) Prostaglandin D2-sensitive, sleeppromoting zone defined in the ventral surface of the rostral basal forebrain. Proc Natl Acad Sci USA 91:11998-12002.

Mihailovic LT (1972) Cortical and subcortical electrical activity in hibernation and hypothermia. In: Hibernation and hypothermia: perspectives and challenges (FE South, JP Hannon, JR Willis, ET Pengelley, NR Albert, eds), pp 487-534. Amsterdam: Elsevier.

Minami T, Okuda-Ashitaka E, Mori HH, Ito S, Hayaishi O (1996) Prostaglandin D2 inhibits prostaglandin E2-induced allodynia in conscious mice. J Pharmacol Exp Ther 278:1146-1152.

Morgan JI, Curran T (1991) Stimulus-transcription coupling in the nervous system: involvement of the inducible proto-oncogenes fos and jun. Annu Rev Neurosci 14:421-451.

Neve R, Perrone-Bizzozero N, Finklestein S, Zwiers H, Bird E, Kurnit D, Benowitz L (1987) The neuronal growth-associated protein GAP-43 (B-50, F1): neuronal specificity, developmental regulation and regional distribution of the human and rat mRNAs. Mol Brain Res 2:177-183.

Nurnberger F, Lee T, Jourdan M, Wang LCH (1991) Seasonal changes in methionine-enkephalin immunoreactivity in the brain of a hibernator, Spermophilus columbianus. Brain Res 547:115-121.

Nurnberger F, Pleschka K, Masson-Pevet M, Pevet P (1997) The somatostatin system of the brain and hibernation in the European hamster (Critcetus). Cell Tissue Res 288:441-447.

O'Hara BF, Fisher S, Oster-Granite ML, Gearhart JD, Reeves RH (1989) Developmental expression of the amyloid precursor protein, growth-associated protein 43, and somatostatin in normal and trisomy 16 mice. Dev Brain Res 49:300-304.

O'Hara BF, Young KA, Watson FL, Heller HC, Kilduff TS (1993) Immediate early gene expression in brain during sleep deprivation: preliminary observations. Sleep 16:1-7.

O'Hara BF, Donovan DM, Lindberg I, Brannock MT, Ricker DD, Moffatt CA, Klaunberg BA, Schindler C, Chang TSK, Nelson RJ, Uhl GR (1994) Proenkephalin transgenic mice: High testis expression and possible infertility. Mol Reprod Dev 38:275-284.

O'Hara BF, Andretic R, Heller HC, Carter DB, Kilduff TS (1995) GABA-A, GABA-C, and NMDA receptor subunit expression in the suprachiasmatic nucleus and other brain regions. Mol Brain Res 28:239-250.

O'Hara BF, Watson FL, Wiler SW, Young KA, Bitting L, Heller HC, Kilduff TS (1997) Daily variation of CNS gene expression in nocturnal vs diurnal rodents and in the developing brain. Mol Brain Res 48:73-86.

Pohl H (1987) Circadian pacemaker does not arrest in deep hibernation. Evidence for desychronization from the light cycle. Experientia 43:293-294.

Pompeiano M, Cirelli C, Tononi G (1994) Immediate early genes in spontaneous wakefulness and sleep: expression of c-fos and NGFI-A mRNA and protein. J Sleep Res 3:65-81.

Popov V, Bocharova L (1992) Hibernation-induced structural changes in synaptic contacts between mossy fibers and hippocampal pyramidal neurons. Neuroscience 48:53-62.

Popov V, Bocharova L, Bragin A (1992) Repeated changes of dendritic morphology in the hippocampus of ground squirrels in the course of hibernation. Neuroscience 48:45-51.

Ram A, Pandey H, Matsumura H, Kasahara-Orita K, Nakajima T, Ta- 
kahata R, Satoh S, Terao A, Hayaishi O (1997) CSF levels of prostaglandins, especially the level of prostaglandin D2, are correlated with increased propensity towards sleep in rats. Brain Res 751:81-89.

Rhyner TA, Borbely AA, Mallet J (1990) Molecular cloning of forebrain mRNAs which are modulated by sleep deprivation. Eur J Neurosci 2:1063-1073.

Ryseck RP, Bravo R (1991) c-jun, JUN B, and JUN D differ in their binding affinities to AP-1 and CRE consensus sequences: effect of FOS proteins. Oncogene 6:533-542.

Sheng M, Greenberg ME (1990) The regulation and function of c-fos and other immediate early genes in the nervous system. Neuron 4:477-485.

Sherin JE, Elmquist JK, Torrealba F, Saper CB (1998) Innervation of histaminergic tuberomammillary neurons by GABAergic and galaninergic neurons in the ventrolateral preoptic nucleus of the rat. J Neurosci 18:4705-21.

Skene J, Jacobson R, Snipes G, McGuire C, Norden J, Freedman J (1986) A protein induced during nerve growth, GAP-43, is widely distributed and developmentally regulated in rat CNS. J Neurosci 6:1843-1855.

Srere HK (1995) Molecular and structural analysis of mammalian liver during hibernation. $\mathrm{PhD}$ thesis, University of Colorado Health Science Center, Denver, CO.

Srere HK, Wang LC, Martin SL (1992) Central role for differential gene expression in mammalian hibernation. Proc Natl Acad Sci USA 89:7119-7123.

Sutin EL, Kilduff TS (1992) Circadian and light-induced expression of immediate early gene mRNAs in the rat suprachiasmatic nucleus. Mol Brain Res 15:281-290.

Takahata R, Matsumura H, Eguchi N, Kantha S, Satoh S, Sakai T, Kondo N, Hayaishi O (1996) Seasonal variation in levels of prostaglandins $\mathrm{D} 2, \mathrm{E} 2$, and $\mathrm{F} 2(\alpha)$ in the brain of a mammalian hibernator, the Asian chipmunk. Prostaglandins Leukot Essent Fatty Acids 54:77-81.

Takamatsu N, Kojima M, Taniyama M, Ohba K, Uematsu T, Segawa C, Tsutou S, Watanabe M, Kondo J, Kondo N, Shiba T (1997) Expression of multiple a1-antitripsin-like genes in hibernating species of the squirrel family. Gene 204:127-132.

Trachsel L, Edgar D, Heller HC (1991) Are ground squirrels sleep deprived during hibernation? Am J Physiol 29:R1123-R1129.

Urade Y, Kitahama K, Ohishi H, Kaneko T, Mizuno N, Hayaishi O (1993) Dominant expression of mRNA for prostaglandin D synthase in leptomeninges, choroid plexus, and oligodendrocytes of the adult rat brian. Proc Natl Acad Sci USA 90:9070-9074.

Walker JM, Glotzbach SF, Berger RJ, Heller HC (1977) Sleep and hibernation in ground squirrels (Citellus spp): electrophysiological observations. Am J Physiol 223:R213-R221.

Wang LCH (1993) Is endogenous opiod involved in hibernation? In: Life in the cold (Carey C, Florant G, Wunder B, Horwitz B, eds). Boulder, CO: Westview.

Wilson BE, Deeb S, Florant GL (1992) Seasonal changes in hormonesensitive and lipoprotein lipase mRNA concentrations in marmot white adipose tissue. Am J Physiol 262:R177-R181. 